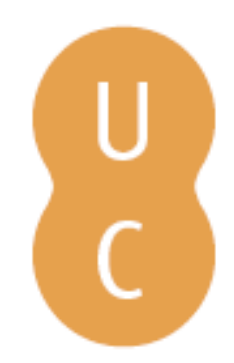

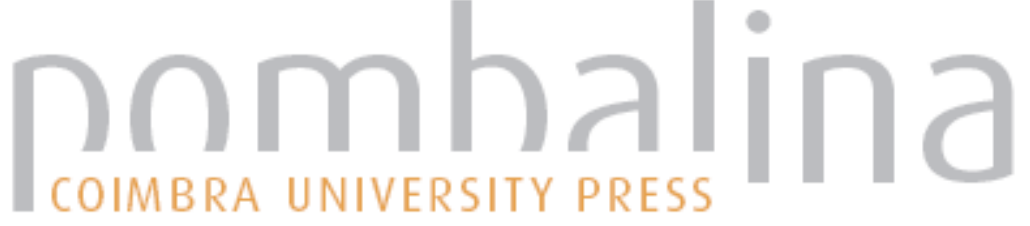

\section{Sem título, 2000, técnica mista, dimensões variáveis}

Autor(es): $\quad$ Carvalho, F. J. Craveiro de

Publicado por: Imprensa da Universidade de Coimbra; Gravida

URL

persistente:

URI:http://hdl.handle.net/10316.2/32602

DOI:

DOI:http://dx.doi.org/10.14195/978-989-26-0485-5_18

Accessed : $\quad$ 26-Apr-2023 07:10:11

A navegação consulta e descarregamento dos títulos inseridos nas Bibliotecas Digitais UC Digitalis, UC Pombalina e UC Impactum, pressupõem a aceitação plena e sem reservas dos Termos e Condições de Uso destas Bibliotecas Digitais, disponíveis em https://digitalis.uc.pt/pt-pt/termos.

Conforme exposto nos referidos Termos e Condições de Uso, o descarregamento de títulos de acesso restrito requer uma licença válida de autorização devendo o utilizador aceder ao(s) documento(s) a partir de um endereço de IP da instituição detentora da supramencionada licença.

Ao utilizador é apenas permitido o descarregamento para uso pessoal, pelo que o emprego do(s) título(s) descarregado(s) para outro fim, designadamente comercial, carece de autorização do respetivo autor ou editor da obra.

Na medida em que todas as obras da UC Digitalis se encontram protegidas pelo Código do Direito de Autor e Direitos Conexos e demais legislação aplicável, toda a cópia, parcial ou total, deste documento, nos casos em que é legalmente admitida, deverá conter ou fazer-se acompanhar por este aviso.

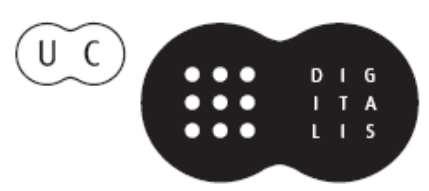


(Página deixada propositadamente em branco) 
MARIA PAULA SERRA DE OLIVEIRA

Coordenadora

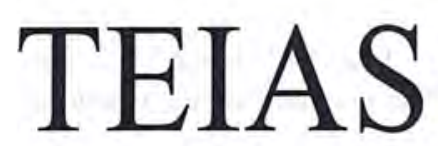

MATEMÁTICAS

Frentes na Ciência e na Sociedade 
(C) Gradiva - Publicações, L. da / Imprensa da Universidade de Coimbra, 2004 Coordenação editorial: Maria Paula Serra de Oliveira

Tradução: Artur Soares Alves

Carlota Isabel Leitão Pires Simões

Francisco José Craveiro de Carvalho

João Filipe Cortez Rodrigues Queiró

José Miguel Dordio Martinho de Almeida Urbano

Lia Sandra dos Santos

Mário da Silva Rosa

Paulo Eduardo Aragão Aleixo Neves de Oliveira

Revisão do texto: Isabel Pedrome

Capa: António Barros [Imprensa da Universidade. Coimbra], com imagem de

E. M. de Melo e Castro, "Fract 010 explod MC", Dezembro de 2003

[Fractal original gerado no Fractint com tratamento no Photoshop 7.0]

Infografia: Estúdios Estímulus [design]

Paginação: António Resende e Victor Hugo Fernandes

Impressão e acabamento: G.C. - Gráfica de Coimbra, L. da

Reservados os direitos para Portugal por:

Gradiva - Publicações, L. ${ }^{\text {da }}$ e Imprensa da Universidade de Coimbra

Gradiva - Publicações, L. ${ }^{d a}$

Rua Almeida e Sousa, 21, r/c, esq. • 1399-041 Lisboa

Telefs. $213974067 / 8 \cdot 213971357 \cdot 213953470$

Fax $213953471 \cdot$ Email: gradiva@ip.pt

URL: http://www.gradiva.pt

Imprensa da Universidade de Coimbra

Rua Antero de Quental, 195 • 3000-033 Coimbra

Telefs. 351239853110

Fax 3512398531 19 e-mail: fjrpress@ci.uc.pt

URL: http://www.imp.uc.pt

ISBN: 972-662-970-5

1." edição: Maio de 2004

Depósito legal n. ${ }^{\circ} 210431 / 04$

OBRA PUBLICADA COM O PATROCÍNIO DE:

CENTRO DE MATEMÁTICA DA UNIVERSIDADE DE COIMBRA DEPARTAMENTO DE MATEMÁTICA DA UNIVERSIDADE DE COIMBRA

FCT Fundação para a Ciência e a Tecnologia

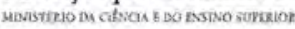


F. J. Craveiro de Carvalho

Departamento de Matemática

Universidade de Coimbra

\title{
Sem título, 2000, técnica mista, dimensões variáveis
}

\author{
Ah, there's no excitement to beat the \\ excitement of proving a theorem! Until \\ you find out the next day that it's wrong! \\ Cathleen Synge Morawetz
}

\begin{abstract}
Barbara Hepworth, Carlos de Oliveira, Wallace Stevens são figuras marcantes em vários universos culturais do século xx. Procurarei usar alguns aspectos do seu trabalho como pontos de apoio possíveis para estabelecer algumas pontes entre a arte e a matemática. A abordagem é ingénua, naturalmente, e deverá ser lida, basicamente, como indicativa da importância que concedo à arte como espaço de fruição do mundo.
\end{abstract}

\section{Salto em Altura}

«Fernando Pessoa dizia:

Aconteceu-me um poema.

A minha maneira de escrever fundamental é muito próxima deste 'acontecer'. O poema aparece feito, emerge, dado (ou como se fosse dado). Como um ditado que escuto e noto.» 
São palavras de Sophia de Mello Breyner Andresen (1972), que, mais adiante, continua:

«Deixar que o poema se diga por si, sem intervenção minha (ou sem intervenção que eu veja), como quem segue um ditado (que ora é mais nítido, ora mais confuso), é a minha maneira de escrever.»

Não creio que posto perante uma questão semelhante houvesse algum matemático que pudesse dar uma resposta próxima da de Sophia. Tive no Verão de 1997 a oportunidade de entrevistar o matemático norte-americano Robert Osserman (F. J. Craveiro de Carvalho et al., 1999), Osserman é o autor do livro de divulgação Poesia do Universo (Robert Osserman, 1995), onde, a certa altura, refere uma afirmação de David Hilbert sobre um estudante que decidira abandonar a matemática:

Bom, ele não tinha imaginação suficiente para ser um matemático.

Perante a minha pergunta sobre o que é necessário para se «fazer», se ter um matemático, Osserman referiu características como a intuição e a visualização geométricas, o perfeito dominio das diferentes técnicas, a capacidade de cálculo, o conhecimento enciclopédico, existindo em conjunto ou separadamente, mas concluiu de uma forma definitivá:

A única qualidade que nunca vi ausente è a disposiçâo para trabalhar duramente.

Num vértice distante da posição de Sophia temos um poeta como Carlos de Oliveira. O excerto seguinte é formado por parte do penúltimo e pelo segmento final do poema «Salto em Altura», publicado inicialmente no volume Entre duas Memórias (Carlos de Oliveira, 1971) (onde, a despropósito, diga-se, aparece um dos poemas que tornam maior a poesia portuguesa, Refiro-me à «Descrição da Guerra em Guernica»).

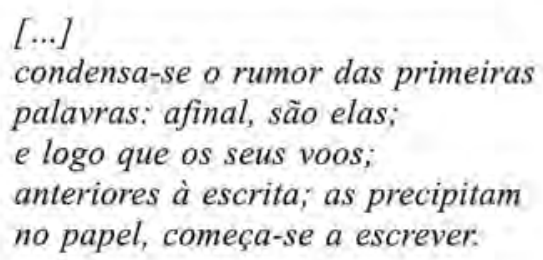




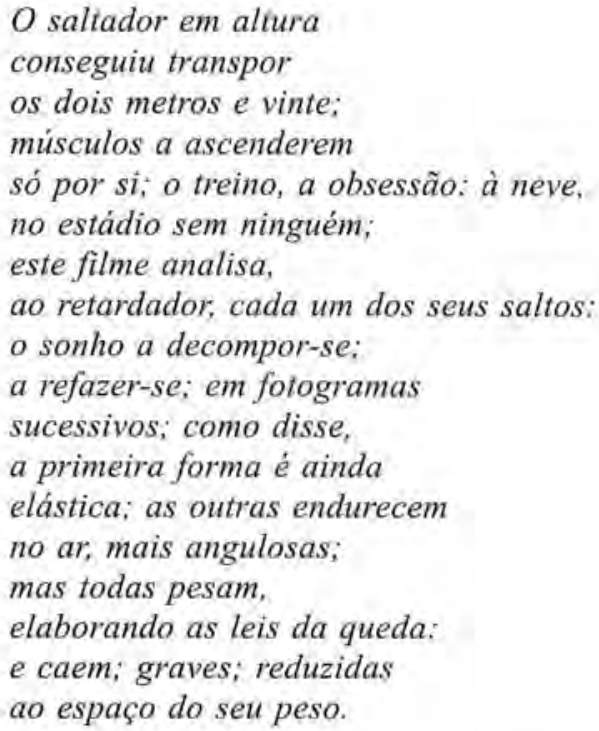

Carlos de Oliveira referir-se-á ao seu trabalho poético. No entanto, é-me possível, apoiado na minha experiência de investigador matemático, isolar algumas das características do meu próprio trabalho: a leveza e a alegria das primeiras ideias (a primeira forma é ainda / / elástica), pequenas construções mentais (os seus voos; / / anteriores à escrita), o esforço e a solidão (músculos a ascenderem só por si; o treino... // no estádio sem ninguém), a verificação exaustiva e o desalento (este filme analisa, / / ao retardador, cada um dos seus saltos: / / o sonho a decompor-se; a refazer-se), os resultados que acabam por se impor como se de forma natural e evidente (e caem; graves; reduzidas / / ao espaço do seu peso) e, finalmente, o conseguimento (o saltador em altura // conseguiu transpor / / os dois metros e vinte) e o processo a recomeçar.

Há, sem dúvida, na história dessas coisas, registos de exemplos matemáticos de revelação que, aparentemente, contrariam o que acabo de referir. Digo aparentemente porque esses instantes perfeitos apenas ocorrem depois de trabalho árduo e continuado, que estará ausente em Sophia. Citarei dois, dos máis emblemáticos, possivelmente.

O primeiro exemplo passa-se com W. R. Hamilton e tem a ver com a sua tentativa de obter em dimensões mais altas, começando com a dimensão 3, um produto análogo ao dos números complexos. Era o chamado problema da «multiplicação dos ternos». A história ocorreu em 16 de Outubro de 1843 (S. A. Robertson, 1974). 
Hamilton caminhavà com a esposa ao longo do Royal Canal a caminho de uma sessão da academia em Dublin. Embora fossem falando de vez em quando, a sua mente estava ocupada com outros pensamentos que, finalmente, deram resultado, culminando o trabalho intenso de muitos anos. Hamilton não resistiu e, ao passarem pela Brougham Bridge, gravou na pedra com uma faca as igualdades fundamentais do produto dos quaterniões:

$$
i^{2}=j^{2}=k^{2}=i j k=-1 \text {. }
$$

O outro caso passou-se com Henri Poincaré, que conta (1947):

Nessa altura deixei Caen, onde então vivia, para participar numa conferência geológica organizada pela Escola de Minas. As peripécias da viagem fizeram-me esquecer os meus trabalhos matemáticos. Quando chegámos a Coutances subimos para um autocarro para ir não sei aonde. No momento em que punha o pé no degrau veio-me a ideia, sem que aparentemente nada nos meus pensamentos anteriores me tivesse preparado para isso, de que as transformações usadas para definir as funções fuchsianas eram idênticas às da geometria não euclidiana. Não o verifiquei, não tive tempo para o fazer, uma vez que reatei a conversa logo que me sentei, mas senti logo uma certeza absoluta. De volta a Caen verifiquei o resultado para tranquilizar o meu espirito.

Sem o dramatismo destes dois exemplos, todo o investigador matemático poderá contar pequenas histórias semelhantes. Mas o que há aqui a realçar é que a fluência e a facilidade matemáticas, tão apreciadas, são sempre muito mais conseguidas do que espontâneas, Como de resto acontece ainda com alguma poesia. $\mathrm{O}$ exemplo seguinte chega-me pela mão acolhedora de Eugénio de Andrade (1995).

Há um belissimo poema de Antonio Machado que me acompanha há mais de vinte anos. $\dot{E}$ um poema breve, um dos raros poemas que sei de cor:

La plaza tiene una torre, la torre tiene un balcón, el balcón tiene una dama, 
la dama una blanca flor. Ha pasado un caballero - quién sabe por qué pasó! y se ha llevado la plaza con su torre y balcón, com su balcón y su dama, su dama y su blanca flor.

São só dez versos, todos de arte menor, como se diz nos compêndios, e não há nada aqui que não seja maior. Nada falta, nada sobra: tudo é simultaneamente leve e denso, límpido e misterioso, simples e complexo... Pois bem, o poema de Machado, de tâo exemplar espontaneidade, teve uma primeira versão de nada menos nada mais que vinte e oito versos e, desses vinte e oito versos, só dois passaram intactos, e um deles com díferença de pontuação, à versão definitiva...

Não menos extremas são as palavras de João Cabral de Melo Neto (Arnaldo Saraiva, 2000):

Tem poemas meus que levaram anos a escrever, como aquele «Tecendo a manhã» de A Educação pela Pedra: passei praticamente dez anos para o concluir ${ }^{1}$.

Para as palavras de João Cabral encontramos paralelo na afirmação seguinte de E. C. Zeeman (2001):

No més passado ${ }^{2}$ consegui provar um teorema que conjecturei há vinte e cinco anos sobre a teoria da proporção de Eudoxus.

\section{UMA SERPENTE $\infty$}

Há outros sinais mais visiveis que denunciam a proximidade entre a poesia e a matemática. Um olhar, que nem precisa de ser muito atento, sobre a poesia portuguesa do século XX permite detectar, com facilidade,

I Trata-se de um poema com dezasseis versos.

2 Janeiro de 2000. 
a utilização de palavras conotadas com ideias matemáticas, desviadas ou não da sua área semântica. Eís alguns exemplos significativos:

\section{A ESFERICIDADE OU FEROCIDADE}

qualidade de que gozam alguns

sólidos quando se viram

para nós ${ }^{3}$

(Luiza Neto Jorge, 1966)

\section{CATEdral de Burgos}

A catedral de Burgos tem trinta metros de altura

e as pupilas dos meus olhos dois milimetros de abertura.

Olha a catedral de Burgos com trinta metros de altura! (António Gedeão, 1971)

\section{AS COORDENADAS LIRICAS \\ Desviou-se o paralelo um quase nada \\ A geométrica forma dos meus passos procura um mar redondo, \\ Em cada esfera desenho o meu refúgio \\ - as minhas coordenadas.}

(Fernando Botelho, 1951)

${ }^{3}$ Há uma outra versão, posterior, e que surge, por exemplo, em Os Sitios Sitiados, deste poema:

$$
\begin{aligned}
& \text { qualidade perigosa a de alguns } \\
& \text { sólidos quando perdidos se viram } \\
& \text { para nós }
\end{aligned}
$$

Optei pela versão original, por, em minha opinião, a segunda versão ser significativamente mais fraca. 
E poderiamos não ficar por aqui. Melhor do que eu, sobre este assunto falou Manuel Portela na conferência de abertura da exposição «A Matemática na Poesia Portuguesa», realizada no Departamento de Matemática da Universidade de Coimbra em 1999.

Por vezes o poema revela, da matemática, uma proximidade mais subtil e mais profunda. Um exemplo é «A história do frasco» ${ }^{4}$ do poeta americano Wallace Stevens. O inicio é agressivo e insólito:
Pousei um frasco no Tennessee,
Um frasco redondo, sobre um outeiro.
E o matagal bravio veio
Cercar aquele outeiro.
O matagal ergueu-se, numa vénia,
e espraiou-se em seu redor; alinhado.
Redondo o frasco no chão.
E alto no seu porte aéreo.
Dominou tudo ali à volta.
Um frasco cinzento e vazio.
Sem dar por ave ou moita,
Como nada mais no Tennessee 5 .

Como diz W. M. Priestley (1990), o frasco de Stevens talvez fosse um poema. Ou um momento de paixão, acrescento eu. Contudo o poema tem-se prestado a uma leitura matemática, baseada na ideia da ordenação que um sistema de referência e as coordenadas que lhe estão associadas permitem introduzir. Aqui o sistema seria tridimensional, com a terceira dimensão dada pela verticalidade do frasco e, indo talvez um pouco longe de mais, pode associar-se, como faz Jonathan Holden (1990), a letra $O$, de origem do sistema de referência, à boca redonda do frasco.

Mais perto de nós temos uma das «Tisanas» de Ana Hatherly (1997);

Era uma vez uma serpente infinita. como era infinita não havia maneira de se saber onde estava a sua cabeça. de cada vez que se lhe tirava uma vértebra não fazia falta nenhuma podia-se mesmo parti-la deslocá-la emendá-la. ficava sempre infinita. quem quisesse levar-lhe um bocado para casa podia pô-lo na parede e contemplar um fragmento da serpente infinita.

${ }^{4}$ «Anecdote of the jar».

${ }^{5}$ Este poema encontra-se também traduzido em Ficção Suprema, Wallace Stevens, publicado pela editora Assirio e Alvim. 
Quem tiver alguma familiaridade com a teoria de conjuntos reconhecerá tratar-se de uma variação sobre o facto de existirem conjuntos com o mesmo número de elementos que algumas das suas partes. Em particular, o número de elementos de um conjunto infinito não se altera se se lhe retirar um subconjunto finito (Klaus Jänich, 1984).

A mesma ideia está subjacente no cartoon que se reproduz a seguir, que se refere a uma viagem de estudo de pequenos prodígios matemáticos e se baseia numa nursery rhyme muito cantada nesse tipo de saidas escolares em países de língua inglesa:

Ten green bottles, hanging on a wall, (repete)

And if one green bottle should accidentally fall

There'll be nine green bottles, hanging on the wall.

E continua até chegar a:

One green bottle, hanging on a wall (repete)

And if one green bottle should accidentally fall,

There'll be no green bottles, hanging on the wall.

O cartoon é tirado da revista College Mathematics Journal ${ }^{6}$ (William Dunham, 1992).

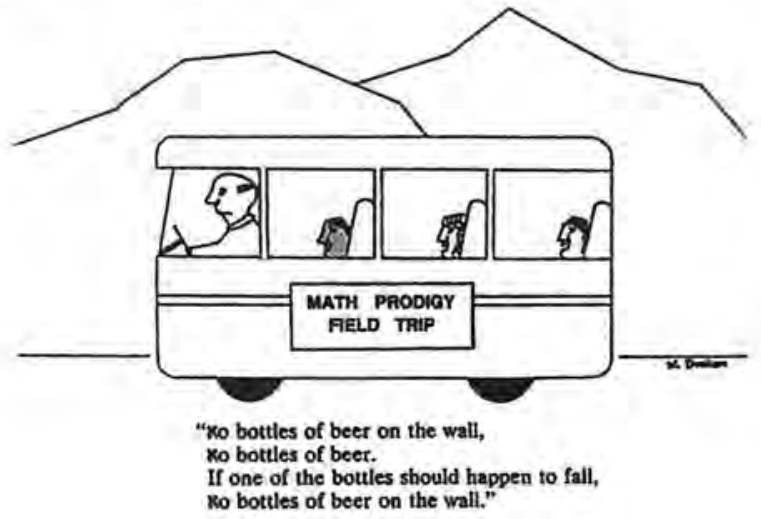

Contributed by William Dunham, Hanover College, Hanover, IN

${ }^{6}$ Reprodução autorizada pela Mathematical Association of America. Reservados todos os direitos. 


\section{AH, MAS E UM TORÖ!}

Aproveitemos o cartoon como pausa de passagem para uma outra forma de arte, a que sou particularmente sensível como geómetra e topologista.

Barbara Hepworth nasceu em 1903 no Yorkshire, Reino Unido, tendo morrido de forma trágica em 1975 em St. Ives, na Cornualha. O seu percurso como escultora acompanhou o de outras figuras famosas: Henry Moore, de quem foi colega e de cuja sombra terá tido alguma dificuldade em se libertar, Naum Gabo e Ben Nicholson, este a quem esteve ligada afectivamente.

Duas características essenciais no trabalho de Hepworth são o uso de buracos enormes, que ocupam por vezes toda a espessura do material em utilização, e o uso de fios tensos. Não se discutirão aqui questões de prioridade, mas refira-se que estas duas características se encontram também no trabalho de Henry Moore, assim como o uso de fios aparece no trabalho de Naum Gabo.

Os fios tensos lembram imediatamente as rectas numa superfície regrada ou, no caso dos elementos equivalentes em desenhos, o campo de rectas tangentes a uma dada curva. Tal não é acidental, já que Hepworth na sua juventude estudou modelos matemáticos em Londres e Paris, mas «deixou a ideia ficar adormecida no seu espírito atê ser capaz de a usar emocional e não matematicamente» (A. M. Hammacher, 1993). De facto, essas familias de rectas surgem em desenhos cujo motivo dominante é o cristal, enquanto nas esculturas a transparência possibilitada pelo uso de fios surge como contraste às ideias de limite ou cerco que materiais como a madeira, a pedra implicam (A. M. Hammacher, 1993). O uso do buraco ou furo confere ao trabalho de Barbara Hepworth um peso topológico enorme. Um matemático conhecedor de alguns aspectos da teoria das superfícies (W. S. Massey, 1967) exclamará:

Ah, mas é um toro! (simples ou múltiplo conforme as circunstâncias).

ou

\section{[...] mas topologicamente é uma esfera.}

Não é só essa atracção topológica, para usar palavras de E, C. Zeeman (2001) ao referir-se a Moore e Hepworth, que me interessa aqui. Toca-me ainda mais a permuta entre matemática e figuração, patente nalguns trabalhos que procurarei evidenciar com exemplos retirados de A. M. Hammacher, 1993. 
Comecemos com as esculturas das figuras $41,42,46$ ou 51 , por exemplo. Trata-se de esculturas compostas por elementos de uma geometria muito despojada e, no entanto, na sua minimalidade, remetem, todas elas, para o intimismo doméstico das naturezas mortas.

Já a uma escultura como a da figura 39 não surpreenderia que em vez de Two Forms a autora tivesse dado um título mais referencial. A ideia do par mãe e filho, que ocorre natural e imediatamente, não impede a mente treinada matematicamente, e conhecedora da igualdade que relaciona os pontos críticos de uma função com o número de Euler (D. R. J. Chillingworth, 1976), de ser instintivamente levada a tentar verificar essa igualdade, no caso da superfície maior, para as funções altura determinadas pelos vectores unitários normais ao plano de apoio. Associando 1 (resp. - 1) a cada ponto da superfície em que o plano tangente é paralelo ao plano de apoio e, localmente, a superfície está inteiramente para um dos lados desse plano (resp. - não está) e somando obter-se-á 2, número de Euler da esfera.

\section{Colagens, citaçôes...}

Limitei-me aqui a destacar apenas algumas áreas de contacto entre a arte e a matemática, não sendo este texto mais que uma colagem de apontamentos breves. Que seja uma colagem poderá não ser inteiramente desapropriado em face do contexto. A referência, a citação, a colagem são instrumentos usados em arte e não o são menos em matemática. Como diz, autorizadamente, W. T. Gowers na sua notável contribuição para Mathematics: Frontiers and Perspectives (V. Arnold et al. 2000), «o progresso é frequentemente o resultado de combinações inteligentes de uma larga variedade de resultados existentes».

\section{AGRADECIMENTOS}

A Carlota Simões, pela preparação das transparências relativas ao trabalho de Barbara Hepworth apresentadas na sessão de Teias Matemáticas; a Manuel Portela, pela tradução, excelente, do poema de Wallace Stevens. 


\section{Referências}

Eugénio de Andrade (1995) - Rosto Precário, Fundação Eugénio de Andrade. Sophia de Mello Breyner Andresen (1972) - Dual, Moraes Editores.

V. Arnold et al. (2000) - Mathematics: Frontiers and Perspectives, American Mathematical Society.

Fernando Botelho (1951) - As Coordenadas Líricas, Távola Redonda - 1." série.

D. R. J. Chillingworth (1976) - Differential Topology with a View to Applications, Pitman Publishing.

F. J. Craveiro de Carvalho et al. (1999) - Our Speaker Today, Departamento de Matemática da Universidade de Coimbra.

William Dunham (1992) - Cartoon, College Mathematics Journal, vol. 23, \#1. António Gedeão (1971) - Poesias Completas, Portugália.

A. M. Hammacher (1993)-Barbara Hepworth, Thames and Hudson.

Ana Hatherly (1997) - 351 Tisanas, Quimera.

Jonathan Holden (1990) - The Poetry of Wallace Stevens, Math. Intelligencer, vol. 12, \#1.

Klaus Jänich (1984) - Topology, Springer-Verlag.

Luiza Neto Jorge (1966) - O Seu a Seu Tempo, Ulisseia.

W. S. Massey (1967) - Algebraic Topology: an Introduction, Harcourt, Brace \& World, Inc.

Carlos de Oliveira (1971) - Entre Duas Memórias, Publicações Dom Quixote. Robert Osserman (1995) - Poesia do Universo, Difusão CulturaI.

Henri Poincaré (1947) - Science et Méthode, Flammarion.

Manuel Portela (1999) - A Matemática na Poesia Portuguesa, Departamento de Matemática da Universidade de Coimbra.

W. M. Priestley (1990) - Mathematics and Poetry: How Wide the Gap?, Math. Intelligencer, vol. $12, \# 1$.

S. A. Robertson (1974) - Topological Surprises (Unforeseen Phenomena in High Dimensional Spaces), uma lição inaugural, Universidade de Southampton.

Arnaldo Saraiva (2000) - Conversas com Escritores Brasileiros, edição do Congresso Portugal - Brasil Ano 2000, Porto.

Wallace Stevens (1991) - Ficção Suprema, tradução de Luisa Maria Lucas Queiroz de Campos, Assírio \& Alvim.

E. C. Zeeman (2001) - entrevista em A Jar in Tennessee, F. J. Craveiro de Carvalho e Jorge Picado, Departamento de Matemática da Universidade de Coimbra. 


\section{$\begin{array}{llllll}\text { C I E } & \mathbf{N} & \mathbf{C} & \mathbf{A}\end{array}$}

mitiram realizar com sucesso tarefas tão distintas como a programação de um voo a Marte, a previsão de resultados eleitorais, a explicação do funcionamento de alguns mecanismos do sistema nervoso, ou a abordagem critica de obras de arte e de textos literários. Da ciência à sociedade, dos grandes avanços técnicos à solidez de uma argumentação lógica, a Matemática constrói teias de uma imensa flexibilidade resultante do carácter universal da sua linguagem.

Neste livro, personalidades de diferentes universos dão o seu testemunho sobre a forma como usam as teias matemáticas para tecer a sua própria visão do mundo.

Maria Paula Serra de Oliveira é professora de Matemática na Faculdade de Ciências e Tecnologia da Universidade de Coimbra. 